\title{
Auger Electron Spectroscopy-A Review
}

\section{Bhavyasri K*, Sreshta M, Swethasri R}

Department of Pharmaceutical Analysis, RBVRR Women's College of Pharmacy, Hyderabad, India

\begin{abstract}
A B S T R A C T
Auger electron spectroscopy (AES) is surface sensitive analytical technique mainly, it provides quantitative elemental and chemical state information from surfaces of solid materials. It utilizes a high current, finely focused electron beam as an excitation source. In AES,A sample is probed with electron beam with energy between 3 to 3o Kev which results in ejection of electron in core level, filled by an outer level electron with excess energy being used then, this excess energy used to emit an electron this, emitted electron is said as Auger electron. That result as function of auger electron energy. The resulting spectra is obtained used to determine the composition of samples. The Auger electron kinetic energies are characteristic of emitting atoms and the measurement of their energies is used to identify the elements variation of composition with depth can be determined by ion sputtering technique. Lastly, AES is applicable for detection of thin films, characterization of materials, metallurgy and corrosion science.
\end{abstract}

Key Words: Auger Electron, Mettalurgy, Corrosion.

A R T I C L E I N F 0: Received 11 April 2019; Review Completed 15 May 2019; Accepted 25 May 2019; Available online 15 June 2019

Cite this article as:

Bhavyasri K, Sreshta M, Swethasri R, Auger Electron Spectroscopy-A Review,, Asian Journal of Pharmaceutical Research and Development. 2019; 7(3):100-103, D0I: http://dx.doi.org/10.22270/ajprd.v7i3.508

*Address for Correspondence:

Dr. K. Bhavyasri, Associate Professor, Department of Pharmaceutical Analysis, RBVRR Women's College of Pharmacy, Hyderabad, India

\section{INTRODUCTION}

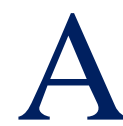
ES was first discovered in 1923 by liese Meitner who was an Austrian physicist and later discovered by Pierre auger in 1925 who was an French physicist. AES is a technique used to study surfaces where electrons are used to probe the materials being analyzed ${ }^{1}$. It is destructive technique but, it is useful in identifying concentrated areas of contamination it can be used quantitatively when standards are available for quantification. Mainly used for quantitative determination of elements present on surfaces except He and $\mathrm{H}$, Depth profiling caused by inert gas sputtering, thin films. $^{2-5}$

\section{PRINCIPLE}

The Auger process is three electron processes when a beam of electrons, typically with an energy range of 3 to $30 \mathrm{Kev}$, strikes a solid atom, a core level electron is ejected producing a single ionized excited atom. An outer electron can fill the resulting vacancy in the core level. Following this radiation less transition, the excess energy of the resulting excited state ion may be removed by emitting either an X-ray or emits an electron which is said as Auger electron. So, AES measures the kinetic energies of emitted electrons. ${ }^{1}$

Energy of the auger electron as detected by the detector can be obtained by the expression:

$\mathrm{Eke}=\mathrm{Ek}-2 \mathrm{El}-\varnothing$

Eke-kinetic energy of the electron as detected by the detector.

Ek-Energy of electron in the $\mathrm{k}$ shell.

El-Energy of electron in the L shell.

$\varnothing$-Work function of the electron. 

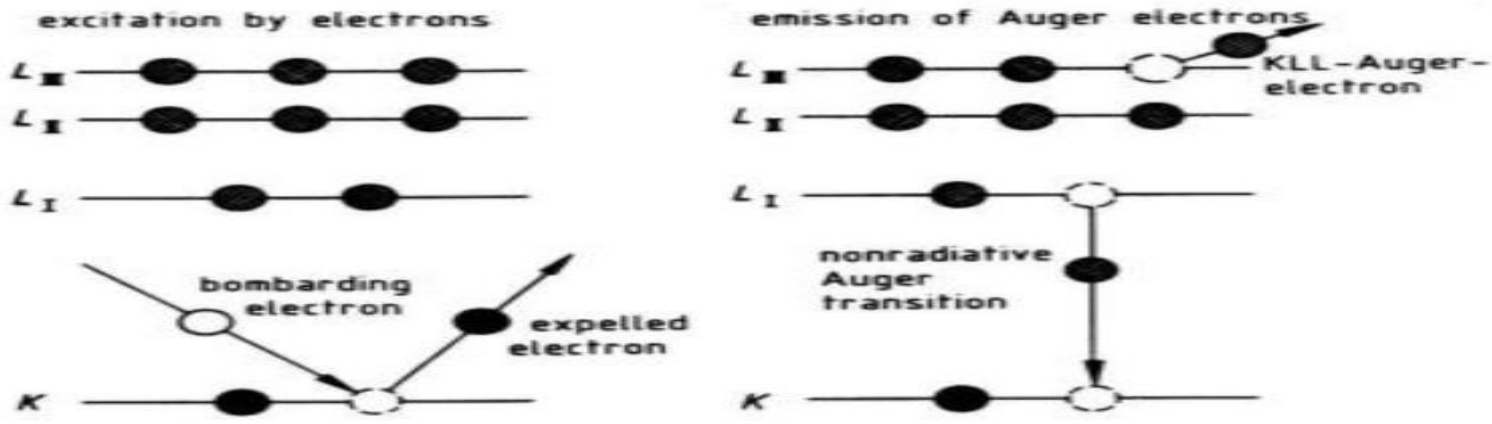

Figure-1: Schematic diagram of electron transitions in case of Auger electron emission

\section{INSTRUMENTATION}

AES consist of following components:

1. UHV Environment

2. Electron optical column

3. Electron analyzer

4. Electron detector

5. Computer Control and Data Display Systems

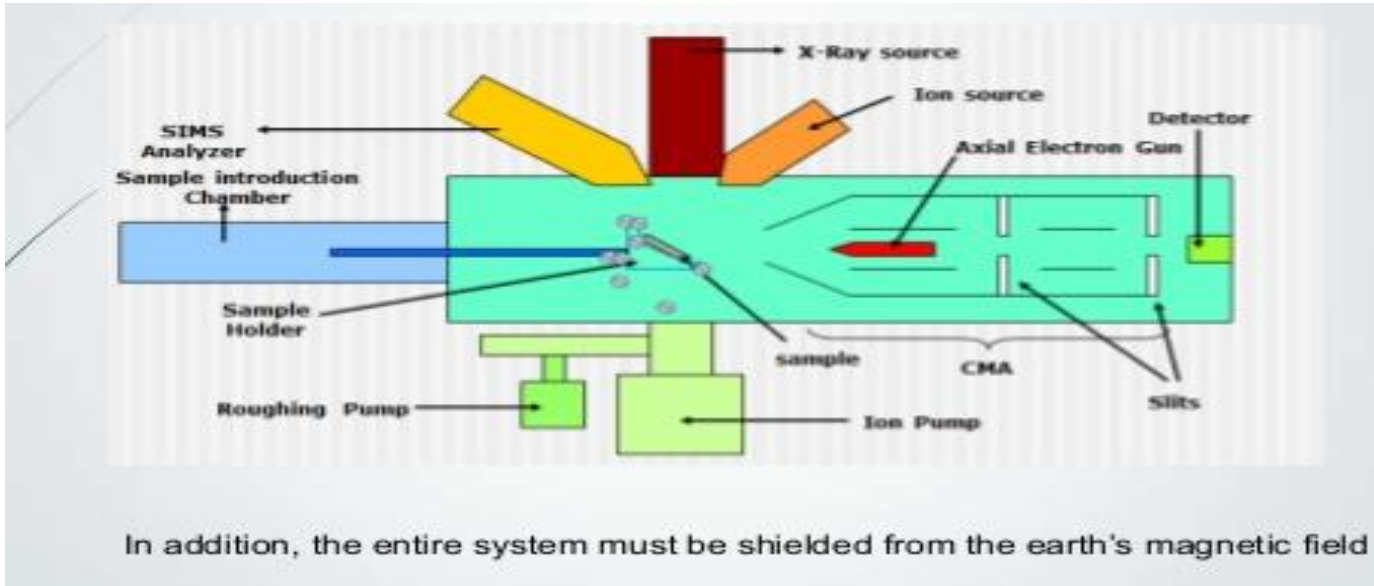

Figure-2: AES Instrument Schematic configration

\section{UHV Environment:}

UHV is an abbreviation of ultra high vacuum, required to remove absorbed gas from the sample, to eliminate the absorption of contaminates on the sample, and to increase the mean free path for electrons.

\section{Electron optical column:}

In AES instrumentation, the electron beam from an electron source is focused on to the specimen surface by a suitable optical column. The electron beam should be small in size with high brightness. The sample to be irradiated with electrons with energy of 2-10 keV and beam current of $10^{-2}$ to $10-5 \mathrm{~A}$. There are four types of electron sources.

The Tungsten thermionic emitter operates at a temperature of $\sim 2700 \mathrm{~K}$ producing a low current density. Because of the low brightness and concurrent large beam size, not used in case of auger experiments.

The Lanthanum hexaboride (LaB6) thermionic emitter, with a lower work function than tungsten, operates at a lower temperature $(\sim 1850 \mathrm{~K})$ and provides for good lateral resolution because of its high current density.
The Cold field emitter, made of a tungsten single crystal, operates at room temperature in the presence of a high electrostatic field and produces high brightness. It is unstable in the presence of residual gases and hence requires pressures of $10^{-10}$ torr.

The Hot field emitter, also known as $\mathrm{ZrO} 2 / \mathrm{W}$ Schottkytype field emitter, operates at $\sim 1800 \mathrm{~K}$ and produces high current densities.

\section{Electron Energy Analyzers:}

Electron energy analyzers are used to measure the number of ejected electrons $(N)$ as a function of electron energy $(E)$. The most commonly used energy analyzers in AES are.

- Cylindrical mirror analyzer (CMA)

- Concentric hemispherical Analyzer $(\mathrm{CHA})^{6-14}$

\section{CMA:}

It composed of electron gun, two cylinders and electron detector. An effected electron comes from the electron gun enter the space between the inner and outer cylinder. The inner cylinder is at ground potential, while outer cylinder is at -ve potential is proportional to the kinetic energy of the electron due to this -ve potential it deflects the electron towards the electron detector. 


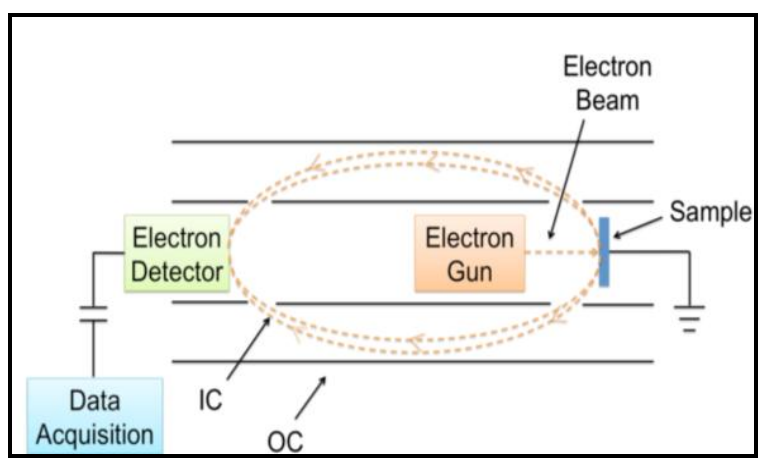

\section{CHA:}

Electrons ejected from the surface enter the input lens, which focuses the electron and retard their energy for better resolution. The electrons enter the hemispheres through an entrance slit. a potential difference is applied to the hemispheres so, that electrons with a small range of energy differences reach the exit slit. Finally, an electrons detector detects them.

Figure 3: Schematic of a cylindrical mirror analyzer

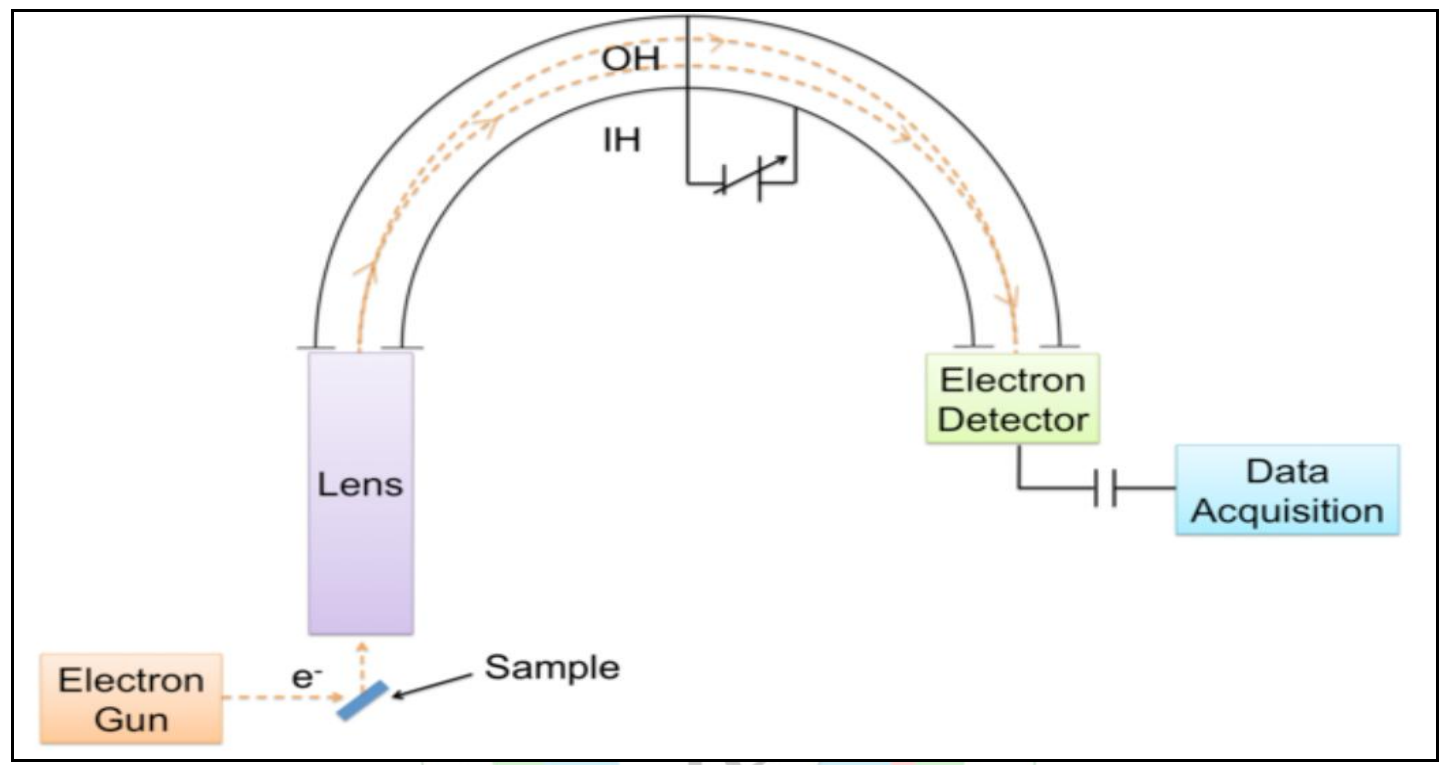

Figure 4: Schematic of a concentric hemispherical analyzer

4. Electron detector: Electrons exiting the analyzer and arriving at the detector are amplified and counted by an electron multiplier, either a channeltron or a micro channel plate (MCP). Electrons striking the specially coated inside of a channeltron, a cone shaped dynode, produce many secondary electrons, which are accelerated toward the anode. A micro channel plate consists of many tiny channeltrons fused together to form a disc. Electron intensity measurements are usually done by pulse counting.

5. Computer Control and Data Display Systems: The computer control system has four majors functions:

(i) Setting up conditions for analysis;

(ii) Acquiring and storing data efficiently;

(iii) Processing data; and

(iv) Displaying results in the form of spectra ${ }^{6-14}$

\section{APPLICATIONS:}

Detection of grain boundary for an al-cu-li alloy: Auger electron spectroscopy was employed to determine grain boundary for an al-cu-li alloy, the li/al ratio of GBS in the naturally aged condition was revealed to be significantly higher than in over aged condition (or in the bulk condition) Grain boundary fracture surfaces for the naturally aged alloy were depleted in cu, where as in the over aged condition the GB fracture surface were depleted in li and enriched in cu relative to the bulk composition.

\section{Detection of corrosion in stainless steel:}

Auger electron spectroscopy can be effective in determining the quality of passivation layers used to prevent the corrosion in stainless steel. If corrosion occurs auger analysis can be instrumental in determine it cause, and auger analysis is capable of detectable very localized corrosion and potential causes. ${ }^{15}$

Detection of ions on glass surfaces: Auger electron spectroscopy is used in the analysis of glass surfaces. Some of the adsorbed and or mobile ions are very difficult to measure in glasses due to their migration under the electron $^{16}$

Depth profiling: providing quantitative compositional information as a function of depth below the surface depth profiles are obtained by employing a controlled sputtering, it is a process in which the ion gun is used to remove a top most layer of the surface of a sample. ${ }^{17}$

\section{CONCLUSION:}

Auger electron spectroscopy is useful for determining the compositions of surface layers to the depth of about $2 \mathrm{~nm}$ for elements above he. It also have spatial resolution greater than or equal to $100 \mathrm{~nm}$, which is about a tenth of the electron probe x-ray micro analyses. This makes this technique well suited to the studies of grain boundaries in metals and alloys. It is also useful for surface segregation studies as in the solving of stress-corrosion problems. Some advantages of using this technique are that it has 
high resolution, precise chemical sensitivity, and it is very good in analyzing semiconductor with sub micrometer features. So, AES can be used to analyze surfaces as small as $10 \mathrm{~nm}$.

\section{REFERNCES:}

1. Briggs D. Auger and X-ray photoelectron spectroscopy. Practical Surface Analysis. 1983; 1(9):533.

2. Chao LC, Yang SH. Growth and Auger electron spectroscopy characterization of donut-shaped $\mathrm{ZnO}$ nanostructures. Applied surface science. 2007; 253(17):7162-65.

3. Kryzhevoi NV, Cederbaum LS. Exploring protonation and deprotonation effects with Auger electron spectroscopy. The journal of physical chemistry letters. 2012; 3(18):2733-37.

4. Gondran CF, Johnson C (et.al) Auger electron spectroscopy depth profile analysis to verify an interfacial reaction at the $\mathrm{Hf} \mathrm{N} / \mathrm{Si} \mathrm{O} 2$ interface. Journal of Vacuum Science \& Technology B: Microelectronics and Nanometer Structures Processing, Measurement, and Phenomena. 2006; 24(5):2457-59.

5. Chung MF, Jenkins LH. Auger electron energies of the outer shell electrons. Surface Science.1970; 22(2):479-485

6. O'Connor DJ, Sexton BA (et.al) Surface analysis methods in materials science. Springer Science \& Business Media; 2013; 24:3-69.

7. Narumand DH, Childs KD. Auger Spectrometers: A Tutorial Review. Applied Spectroscopy Reviews. 2004; 34(3):139-58

8. Briggs D, Grant JT, Surface analysis by Auger and X-ray photoelectron spectroscopy. Surface Spectra; 2012; 31

9. Gunawardane RP, Arumainayagam CR. Auger electron spectroscopy. In Handbook of applied solid state spectroscopy 2006; 451-483.

\section{ACKNOWLEDGEMENT:}

The author would like to express her gratitude to Dr Bhavya Sri and DR.M. Sumakanth for their guidance and reviews, grateful to RBVRR Women's College of pharmacy for help and support.

10. Watts JF, Wolstenholme J. An introduction to surface analysis by XPS and AES, Surface and Interface Analysis.1989; 14(8):48

11. Seah MP, Gilmore IS(et.al) Quantitative AES IX and quantitative XPS II: Auger and X-ray photoelectron intensities and sensitivity factors from spectral digital databases reanalyzed using a REELS database. Surface and Interface Analysis: An International Journal devoted to the development and application of techniques for the analysis of surfaces, interfaces and thin films. 2001; 31(8):77895.

12. Sekine T, Ikeo N,(et.al) Analysis of polymers by auger electron spectroscopy with a cold stage. Surface and interface analysis. 1995; 23(6):386-90.

13. Auger P. Sur l'effet photo électrique composé. Journal de Physique et le Radium.1925; 6(6):205-8.

14. Hofmann S. Advances in sputter depth profiling using AES. Surface and Interface Analysis: An International Journal devoted to the development and application of techniques for the analysis of surfaces, interfaces and thin films. 2003; 35(7):556-63.

15. http://www.nanoscience.co.jp/industry_analysis/pdf/BN1500.pdf

16. https://www.sciencedirect.com/science/article/pii/0022309375900 $68 \mathrm{X}$

17. http://citeseerx.ist.psu.edu/viewdoc/download?doi=10.1.1.610.12 $78 \&$ rep=rep $1 \&$ type $=$ pdf

18. L. E. Davis, N. C. MacDonald(et.al), Handbook of Auger Electron Spectroscopy, Physical Electronics Industries, Inc., 1976 